\title{
Superficial ocular malignancies treated with strontium-90 brachytherapy: long term outcomes
}

\author{
Siddhartha Laskar, MD', Lavanya Gurram, MD', Sarbani Ghosh Laskar, MD', Suresh Chaudhari, DipRP2, \\ Nehal Khanna, MD!, Rituraj Upreti, DipRP2 \\ 'Department of Radiation Oncology, ${ }^{2}$ Department of Radiation Physics, Tata Memorial Hospital, Mumbai, Maharashtra, India
}

\begin{abstract}
Purpose: The incidence of conjunctival malignancies is less than $1 \%$. Though surgical excision remains the mainstay of treatment, the incidence of positive surgical margins and local recurrence rates are high, which is approximately up to $33 \%$ in negative margins and 56\% in positive margins. Radiotherapy reduces the risk of recurrence in these cases. Brachytherapy using $\beta$ emitters such as strontium- 90 ( ${ }^{90} \mathrm{Sr}$ ) is an ideal treatment technique for these tumors with the advantage of treating only a few millimeters of tissue while sparing the underlying normal eye. We report the long term outcomes in the form of local control and late sequelae of patients with conjunctival malignancies treated with ${ }^{90} \mathrm{Sr}$ applicator brachytherapy.

Material and methods: During 1999-2013, 13 patients with conjunctival tumors, treated using ${ }^{90}$ Sr brachytherapy were analyzed. Brachytherapy was either in a post-operative adjuvant or in a recurrent setting. Local control (LC), disease free survival (DFS), overall survival (OS), and late sequelae were evaluated.

Results: The median age at presentation was 47 years (range: 11-71 years). Thirteen patients with 15 tumors were treated. The commonest histology was squamous cell carcinoma. The median dose was 44 Gy over 11 fractions. The median follow up of all the patients was 51 months (range: 3-139 months). The median follow up of patients with carcinoma only was 64 months with a LC and DFS of $90.9 \%$ at 5 years. None of the patients developed $\geq$ grade II Radiation Therapy Oncology Group (RTOG) acute toxicities. One patient developed a focal scar and another developed corneal opacification at the limbus. Vision was not impaired in any of the patients.

Conclusions: Strontium-90 brachytherapy used in early invasive conjunctival malignancies as an adjunct to surgery in primary and recurrent settings, results in optimal disease control and ocular functional outcomes.
\end{abstract}

Key words: brachytherapy, conjunctival tumors, ocular malignancies, ${ }^{90} \mathrm{Sr}$.

\section{Purpose}

The incidence of conjunctival malignancies is rare in India and accounts for less than $1 \%$ of all malignancies. The diagnosis of early cancers is a challenge as the symptoms are nonspecific and mimic benign conditions such as pingeucula, pterygium, etc. [1, 2]. The most common site of occurrence is in the limbal region [1]. Squamous cell carcinomas (SCC) are more common than basal cell carcinoma (BCC) [2]. The main treatment modality for these cancers is excision with adequate margins of $3-4 \mathrm{~mm}$ [3]. Recurrences are high in the range of $33-56 \%$ in tumors with inadequate margin status and greater depth of invasion with intraocular extension [3, 4, 5]. The salvage of these tumors are mainly with enucleation and exenteration [6]. Radiotherapy plays an important role in preventing these local recurrences when used in the adjuvant setting appropriately [6, 7]. There are very few studies reporting the outcomes of patients treated with brachytherapy. In this study, we report the local control rates, overall survival, and sequelae of patients treated with strontium-90 $\left({ }^{90} \mathrm{Sr}\right)$ source applicator brachytherapy.

\section{Material and methods}

Thirteen patients diagnosed to have conjunctival tumors treated with ${ }^{90} \mathrm{Sr}$ brachytherapy were included in the study. All the patients underwent excision of the tumor prior to referral to our institute (excisional biopsy in 12 eyes, excision with $1 \mathrm{~mm}$ margin clearance in 1 eye, $2 \mathrm{~mm}$ margin clearance in 1 eye, and 1 eye with wide excision, in which margin status not commented). Histopathological review was obtained in all the cases before initiation of therapy. Visual acuity and local status of the eye was evaluated. Consent was obtained from all the patients.

\section{Indications}

Strontium-90 brachytherapy was delivered as an adjuvant following primary tumor excision or after excision of 
recurrent disease. The indications of radiotherapy were unknown, margin status, close margins of $\leq 2 \mathrm{~mm}$, recurrent disease after re-excision, deep invasion, which was mainly stromal invasion, and residual carcinoma in situ.

\section{Procedure}

Patients were explained the treatment process in detail prior to the application. The target volume was determined by pre-excision clinical details, which included pictorial representation. A single field was applied in the area involved with the ${ }^{90} \mathrm{Sr}$ applicator of $12 \mathrm{~mm}$ active diameter. The procedure was performed after application of topical anesthesia. The eye gaze was fixed to the opposite side of the treatment area in order to completely visualize the target volume (Figure 1A). The hand held applicator was then placed over the target area by the radiation oncologist for the treatment duration, which was calculated based on the source activity and prescribed dose (Figure 1B). Dose was prescribed to the surface of the conjunctiva. The treatment time was checked by the physicist with a timer. Quality assurance was ensured at every step of the procedure, including strict documentation of individual patient treatment record.
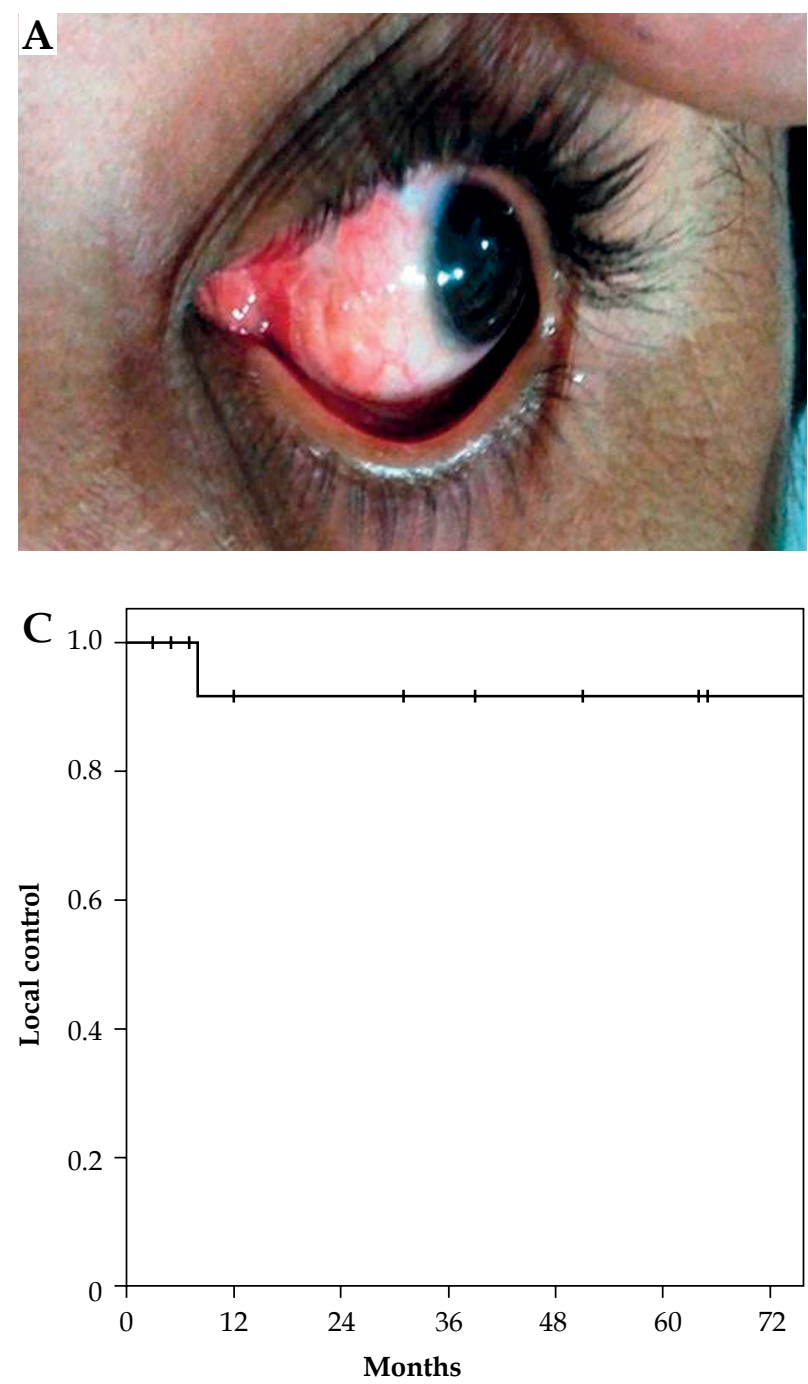

\section{Strontium-90 applicator}

Strontium-90, a $\beta$ emitter with a half-life of 28.9 years was used. The decay process is mainly by yttrium-90 $\left({ }^{90} \mathrm{Y}\right)$ emission with maximum $\beta$ energy of $2.28 \mathrm{MeV}$ and average of $0.70 \mathrm{MeV}$, which is useful for treatment. The SIA-6 applicator was used. The applicator is concave in shape with a radius of curvature of $10 \mathrm{~mm}$ and an active diameter of $12 \mathrm{~mm}$. It has a handle of $15 \mathrm{~cm}$ with a bend at $12 \mathrm{~cm}$ for better positioning.

\section{Dose}

Dose of 30-50 Gy was delivered with a median of $44 \mathrm{~Gy}$ in once daily fractionated regimen. The dose prescription was mainly based on the indication of treatment. Dose per fraction of 0.25-4 Gy was delivered with a median of $4 \mathrm{~Gy} /$ fraction. Three patients received alternate day treatment.

\section{Post treatment evaluation}

Acute reactions during and in the immediate postbrachytherapy period was evaluated and appropriate measures taken. Patients were followed at 3 monthly intervals

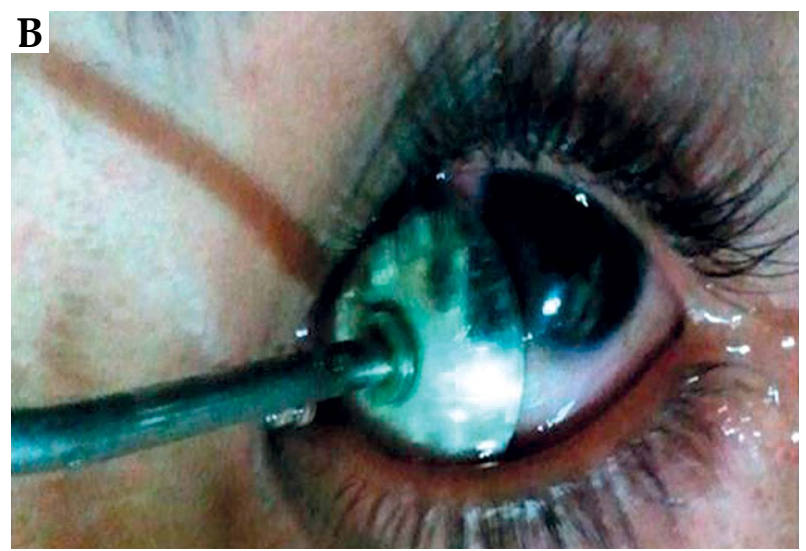

Fig. 1. A) Fixation of gaze towards opposite side prior to treatment. B) Applicator in direct contact with the affected area during treatment. C) Kaplan Meier Curve depicting local control at 5 years 
for 2 years, followed by 6 monthly intervals till 5 years and annually thereafter. Clinical examination of the eye was performed at every follow up and checked for recurrence, conjunctivitis, scarring, and ophthalmological evaluation, which included visual acuity was done annually. When in suspicion for recurrence, the area was excised and histopathology report (HPR) reviewed. Toxicity was assessed with RTOG acute and late toxicity grading system.

\section{Results}

Thirteen patients with 15 tumors were treated prospectively between 1999-2013. Majority of the patients were males (10) and 3 were females. The median age at the time of presentation was 47 years (range: $11-71$ years). Histology was SCC in 8 eyes with 4 of them having grade III histology. One patient had meibomian gland carcinoma, 1 patient had bowenoid actinic keratosis, and 1 patient was diagnosed to have mucosa associated lymphoid tissue lymphoma (MALT lymphoma). All patients had undergone local excision prior to referral to our institute with a median time to presentation of 3 weeks after surgery. The most common site of presentation was the limbus ( 7 patients in medial limbal region and 4 in the lateral limbal region). Three patients had tumor in the nasal conjunctiva and 2 in the temporal conjunctival region. Eight tumors occurred in the right side and 7 in the left side. All patients received radiotherapy in the adjuvant setting. Doses were in the range of 30-50 Gy with dose per fraction varying from $2.5 \mathrm{~Gy}$ to $4 \mathrm{~Gy}$. Visual acuity of one patient was $6 / 18$ and $6 / 6$ in 12 patients. One patient had under- gone cataract surgery prior to treatment. Fundal examination revealed posterior vitreous detachment in 1 patient with a known history of hypertension. The characteristics of treated patients are given in Table 1 . The median time to adjuvant treatment from the date of surgery was 7 weeks (range: 1-26 weeks). The total treatment duration ranged from 10 to 29 days with a median of 13 days. This was because 3 patients received alternate day treatment.

The median follow up of all the patients was 51 months (range of 3-139 months). Median follow up of patients with carcinoma was 64 months (range of 3-139 months). Two patients of SCC developed local recurrences. One of them had received alternate day treatment. Both patients were salvaged successfully with re-excision. One patient received re-irradiation with ${ }^{90} \mathrm{Sr}$ brachytherapy after excision and is locally controlled at last follow up. The local control rates of patients with carcinoma at 5 years was 90.9\% (95\% CI: 51-98) as shown in Figure 1C. None of the patients developed regional nodal or distant metastases.

Tolerance to treatment was good in all the patients, none of them developed $\geq$ grade II RTOG acute reactions. One patient developed a limbal scar and 1 patient developed opacification at limbus. Vision was not impaired in any of the patients. No significant late sequelae such as cataract, limbal stem cell deficiency, or chronic eye pain were observed in our study.

\section{Discussion}

Squamous cell carcinomas and lymphomas are the most common non-melanocytic malignant ocular surface

Table 1. Patient, tumour, and treatment characteristics

\begin{tabular}{|c|c|c|c|c|c|c|c|c|}
\hline No & Gender & Age (years) & HPR & Side & Location & Dose (Gy) & Indication of RT & Status \\
\hline 1 & Female & 19 & SCC & Right & Lat Limb & 40 & Margins unknown & Controlled \\
\hline 2 & Male & 71 & SCC & Left & Med Limb & 40 & Stromal invasion & Controlled \\
\hline 3 & Female & 61 & SCC & Right & Med Limb & 42.5 & Margins unknown & Controlled \\
\hline 4 & Male & 47 & SCC & Left & Nasal & 44 & Margins unknown & Controlled \\
\hline 5 & Male & 26 & SCC & Right & Lat Limb & 44 & $\begin{array}{c}\text { Recurrence, } \\
\text { Margins unknown }\end{array}$ & Controlled \\
\hline 6 & Male & 57 & $\begin{array}{l}\text { Bowenoid } \\
\text { keratosis }\end{array}$ & Left & Temporal & 44 & Margins: $2 \mathrm{~mm}$ & Controlled \\
\hline 7 & Male & 54 & SCC & Left & Limbus & 44 & $\begin{array}{l}\text { Margins unknown } \\
\text { Residual in situ tumor }\end{array}$ & Controlled \\
\hline 8 & Male & 52 & SCC & Left & Med Limb & 44 & Margins unknown & Controlled \\
\hline 9 & Male & 33 & SCC & Right & Limbus & 30 & Margins unknown & Controlled \\
\hline 10 & Male & 66 & $\begin{array}{l}\text { Meibomian } \\
\text { gland } \mathrm{Ca}\end{array}$ & Left & Temporal & 44 & Margins unknown & Controlled \\
\hline 11 & Female & 50 & NHL, MALT & Right & Lower nasal & 40 & Radical RT alone & Controlled \\
\hline 12 & Male & 44 & SCC & Right & Med Limb & 36 & Recurrence, invasive & $\begin{array}{l}\text { Local } \\
\text { recurrence }\end{array}$ \\
\hline 13 & Male & $\begin{array}{l}11 \\
14 \\
17\end{array}$ & $\begin{array}{l}\text { SCC } \\
\text { SCC } \\
\text { SCC }\end{array}$ & $\begin{array}{l}\text { Left } \\
\text { Right } \\
\text { Right }\end{array}$ & $\begin{array}{l}\text { Med Limb } \\
\text { Med Limb } \\
\text { Med Limb }\end{array}$ & $\begin{array}{l}44 \\
44 \\
44\end{array}$ & $\begin{array}{l}X P \text {, recurrence, close margin } \\
X P \text {, invasive } \\
X P \text {, invasive }\end{array}$ & $\begin{array}{l}\text { Controlled } \\
\text { Controlled } \\
\text { Controlled }\end{array}$ \\
\hline
\end{tabular}


tumors. The incidence of ocular malignancies in India in general is very low. The primary treatment of conjunctival carcinomas include surgical excision. However, the frequency of recurrences are as high as 30\% in invasive tumors with negative surgical margins and $50 \%$ with positive margins [5, 8]. Adjuvant therapies like brachytherapy, topical chemotherapy with mitomycin-C or 5-fluorouracil, and immunotherapy have been applied with good local rates $[9,10,11]$. The benefit of one treatment over the other has not been proven, due to small number of patients in reported literature, and would be difficult to prove in view in the absence of prospective randomized studies.

Male gender has a higher predilection of developing these tumors, which is similar in our study. The median age at presentation in our study was 47 years. Conjunctival malignancies in the past were seen more commonly in the sixth and seventh decade, however, with increase in HPV epidemic, the age at presentation has decreased [12, 13]. In our study, we did not include the prevalence of HPV in these tumors. One patient with xeroderma pigmentosum developed conjunctival malignancy at the age of 11 years. Early presentation of disease in this condition has been reported in literature [1]. Galor et al. studied the various predictive factors for the development of recurrences after surgical excision. Pathological T size, higher grade, and positive margins showed a significant association with recurrences, and the addition of adjuvant therapies reduced the rate of recurrences likewise in tumors with both positive and negative margins [3]. Similarly, in our study, the margin status had no association after the delivery of adjuvant ${ }^{90} \mathrm{Sr}$ brachytherapy. There was no association with the grade of the tumor also. This may be because of the inconsistent association of grade amongst the studies [1,2].

All patients in the current series had undergone prior excision of the primary tumor. Kearsley et al. and Walsh-Conway et al. have reported improved disease control in patients with positive margins, recurrent tumors, and localized corneo-scleral invasion with the addition of adjuvant brachytherapy $[7,14]$.

Median dose of 44 Gy over 11 fractions was delivered in our group. The dose prescriptions have been varied amongst the various reports ranging from $15 \mathrm{~Gy}$ to $80 \mathrm{~Gy}$ with a mean of 50-56 Gy. Although there is no definite dose response relationship reported for optimal disease control, Kearsley et al. have reported inferior local controls with doses less than $30 \mathrm{~Gy}$ [7]. We recommend a dose of 50-56 Gy EQD2 $(\alpha / \beta: 10)$ for efficient tumor control. Local control rates of $90.9 \%$ at 5 years in our current series are similar to that reported in literature (Table 2).

Various isotopes such as ${ }^{125} \mathrm{I},{ }^{106} \mathrm{Ru},{ }^{90} \mathrm{Sr}$, and ${ }^{103} \mathrm{Pd}$ have been used over the years. Strontium-90 SIA-6 applicator has been used at our institute for two decades. The advantage of strontium is the high dose rate and reduced treatment times as compared to ${ }^{125} \mathrm{I}$ and ${ }^{106} \mathrm{Ru}$, and a long half-life of 28.8 years, thus obviating the need for repeated source replacements. Also, the virtue of $\beta$ emission reduces the chances of corneal ulceration, dry eye as compared to the gamma emitting property of ${ }^{125} \mathrm{I}$. The percentage depth dose (PDD) characteristics of ${ }^{90} \mathrm{Sr}$ SIA-6 applicator is such that when normalized to $100 \%$ at $2 \mathrm{~mm}$ of water, the dose at $3 \mathrm{~mm}$ and $4 \mathrm{~mm}$ is $60.8 \%$ and $28.9 \%$, respectively. For the treatment of surface malignancies, the dose is prescribed at the surface, which reduces the PDD further to $9 \%$ and $1 \%$ at $3 \mathrm{~mm}$ and $5 \mathrm{~mm}$, respectively [19]. Electron beam therapy, which is most commonly used for superficial malignancies also are inferior when compared to brachytherapy. This is because even the lowest energy electrons used clinically $(4 \mathrm{MeV})$ deposit approximately $50 \%$ dose at $1.7 \mathrm{~cm}$, and the dosimetry of electrons in small field sizes is not accurate. The advantages of surface applicators are the fixed geometry and dosimetry in addition to the easy application under direct visual guidance of the radiation oncologist. The shape of the applicator gives gains of treating these conjunctival tumors with ease and comfort to the patient.

Table 2. Literature review

\begin{tabular}{|c|c|c|c|c|c|c|}
\hline Study & $\begin{array}{c}\text { No } \\
\text { of patients }\end{array}$ & Histology & Brachytherapy & LR (No) & Complications & $\begin{array}{l}\text { Follow up } \\
\text { (months) }\end{array}$ \\
\hline Kearsley et al. [7] & 140 & SCC & $\begin{array}{c}123-{ }^{90} \mathrm{Sr} \\
10-\text { Radon ring } \\
7 \text { - Superficial X-ray }\end{array}$ & 3 & $\begin{array}{c}\text { Conjunctival telangectasa (3) } \\
\text { Persistent scleral ulcer (2) } \\
\text { Significant cataract (1) }\end{array}$ & \\
\hline $\begin{array}{l}\text { Walsh-Conway } \\
\text { and Conway [14] }\end{array}$ & 11 & $\begin{array}{l}\text { Melanoma/ } \\
\text { SCC }\end{array}$ & 125 & 0 & $N R$ & 23 \\
\hline Lommatzch [15] & 15 & $\begin{array}{c}10-\mathrm{SCC} \\
4-\mathrm{CIS} \\
1-\mathrm{Ep}\end{array}$ & ${ }^{90} \mathrm{Sr} /{ }^{90} \mathrm{Y}$ & 1 & $\begin{array}{l}\text { Visual loss (2) } \\
\text { Secondary glaucoma (1) } \\
\text { Corneal degeneration (1) }\end{array}$ & \\
\hline Arepalli et al. [16] & 15 & SCC & ${ }^{90} \mathrm{Sr}$ & 0 & $\begin{array}{c}\text { Cataract (13) } \\
\text { Corneal defect (4) } \\
\text { Gaucoma (1) }\end{array}$ & 41 \\
\hline Cerezo et al. [17] & 27 & $\begin{array}{c}15 \text { - Intraepithelial } \\
12-\text { SCC }\end{array}$ & ${ }^{90} \mathrm{Sr}$ & 4 & Cataract (5) & \\
\hline $\begin{array}{l}\text { Sterker and } \\
\text { Lommatzsch [18] }\end{array}$ & 30 & $\mathrm{CIS} / \mathrm{SCC}$ & ${ }^{90} \mathrm{Sr}$ & 1 & $\begin{array}{l}\text { Telangectiasia (1) } \\
\text { Glaucoma (1) } \\
\text { Scleral ulcer (1) }\end{array}$ & 36 \\
\hline
\end{tabular}

$L R$ - local recurrence, SCC - squamous cell carcinoma, CIS - carcinoma in situ, Ep-epidermalization, NR - not reported 
The toxicity rates have been low in our study with 4 patients developing grade I conjunctival teleangectasie, 1 patient developed localized limbal opacification, and 1 patient had minimal scarring at first follow up, which regressed on subsequent follow ups and has conjunctival congestion only at last follow up. No patient developed progressive cataract or glaucoma. The toxicities are lower in our study as compared to other reported literature (Table 2). The local recurrence rates of patients treated with adequate excision and cryotherapy is around 9\% [8]. Kim et al. reported recurrence rates of $28 \%$ with the use of interferon $\alpha 2 b$ [5]. The local rates with the use of chemotherapeutic agents such as mitomycin-C and 5-fluorouracil range from $70 \%$ to $100 \%$ depending on the invasive nature. The major limitation of chemotherapy is the development of limbal stem cell deficiency and hence not extensively used [20,21]. In comparison with other modalities such as chemotherapy and immunotherapy, brachytherapy has offered equal to superior outcomes in terms of control and toxicity profile.

\section{Conclusions}

Strontium-90 brachytherapy can be effectively and safely used in invasive conjunctival malignancies as an adjunctive treatment both in primary and recurrent setting with good control rates. Though there are emerging reports of proton beam therapy, ${ }^{90} \mathrm{Sr}$ has similar advantages in ocular surface malignancies due to the $\beta$ emitting property and continues to be of value.

\section{Disclosure}

Authors report no conflict of interest.

\section{References}

1. Lee GA, Hirst LW. Ocular surface squamous neoplasia. Surv Ophthalmol 1995; 39: 429-450.

2. Carcinoma of the conjunctiva. In: AJCC Cancer Staging Manual. Edge SB, Byrd DR, Carducci MA, Compton CC (eds.). $7^{\text {th }}$ ed. Springer, New York 2009.

3. Galor A, Karp CL, Oellers P et al. Predictors of ocular surface squamous neoplasia recurrence after excisional surgery. Ophthalmology 2012; 119: 1974-1981.

4. Erie JC, Campbell RJ, Liesegang TJ. Conjunctival and corneal intraepithelial and invasive neoplasia. Ophthalmology 1986; 93: 176-183.

5. Kim HJ, Shields CL, Shah SU et al. Giant ocular surface squamous neoplasia managed with interferon alpha- $2 \mathrm{~b}$ as immunotherapy or immunoreduction. Ophthalmology 2012; 119: 938-944.

6. Ben Simon GJ, Schwarcz RM, Douglas R et al. Orbital exenteration: one size does not fit all. Am J Ophthalmol 2005; 139: 11-17.

7. Kearsley JH, Fitchew RS, Taylor RG. Adjunctive radiotherapy with strontium-90 in the treatment of conjunctival squamous cell carcinoma. Int J Radiat Oncol Biol Phys 1988; 14: 435-443.

8. Sudesh S, Rapuano CJ, Cohen EJ et al. Surgical management of ocular surface squamous neoplasms: the experience from a cornea center. Cornea 2000; 19: 278-283.

9. Zehetmayer M, Menapace R, Kulnig W. Combined local excision and brachytherapy with ruthenium-106 in the treat- ment of epibulbar malignancies. Ophthalmologica 1993; 207: 133-139.

10. Tunc M, Erbilen E. Topical cyclosporine-A $(0.05 \%)$ combined with mitomycin $\mathrm{C}(0.01 \%)$ for conjunctival and corneal squamous cell carcinoma. Am J Ophthalmol 2006; 142: 673-675.

11. Shields CL, Naseripour M, Shields JA. Topical mitomycin C for extensive, recurrent conjunctival-corneal squamous cell carcinoma. Am J Ophthalmol 2002; 133: 601-606.

12. Verma V, Defan, S, Sieving P, Chan CC. The role of infectious agents in the etiology of ocular adnexal neoplasia. Surv Ophthalmol 2008; 53: 312-331.

13. Nakamura Y, Mashima Y, Kameyama K et al. Detection of human papillomavirus infection in squamous tumours of the conjunctiva and lacrimal sac by immunohistochemistry, in situ hybridization, and polymerase chain reaction. $\mathrm{Br} J$ Ophthalmol 1997; 81: 308-313.

14. Walsh-Conway N, Conway RM. Plaque brachytherapy for the management of ocular surface malignancies with corneoscleral invasion. Clin Experiment Ophthalmol 2009; 37: 577-583.

15. Lommatzsch P. Beta-ray treatment of malignant epithelial tumors of the conjunctiva. Am J Ophthalmol 1976; 81: 198-206.

16. Arepalli S, Kaliki S, Shields CL et al. Plaque radiotherapy in the management of scleral-invasive conjunctival squamous cell carcinoma: an analysis of 15 eyes. JAMA Ophthalmol 2014; 132: 691-696.

17. Cerezo L, Otero J, Aragón G et al. Conjunctival intraepithelial and invasive squamous cell carcinomas treated with strontium-90. Radiother Oncol 1990; 17: 191-197.

18. Sterker I, Lommatzsch P. Results of treatment in malignant epithelial conjunctival tumors. Ophthalmologe 1993; 90: 62-65.

19. Pajic B, Greiner RH. Long term results of non-surgical, exclusive strontium-/yttrium- 90 beta-irradiation of pterygia. Radiother Oncol 2005; 74: 25-29.

20. Parrozzani R, Lazzarini D, Alemany-Rubio E et al. Topical $1 \%$ 5-fluorouracil in ocular surface squamous neoplasia: a long-term safety study. Br J Ophthalmol 2011; 95: 355-359.

21. Shields CL, Demirci H, Marr BP et al. Chemoreduction with topical mitomycin $C$ prior to resection of extensive squamous cell carcinoma of the conjunctiva. Arch Ophthalmol 2005; 123: 109-113. 